\title{
A new placodont sauropterygian from the Middle Triassic of the Netherlands
}

\author{
Nicole Klein and Torsten M. Scheyer \\ Acta Palaeontologica Polonica 59 (4), 2014: 887-902 doi: http://dx.doi.org/10.4202/app.2012.0147
}

A new genus and species of a non-cyamodontoid placodont is described on the basis of an incomplete and disarticulated skeleton from Winterswijk, the Netherlands, dated as early Anisian (Lower Muschelkalk). The new taxon is unique in a ventrolateral expansion of the neural arches of the posterior presacral and sacral vertebrae, in which the transverse process is incorporated. It has a round, plate-like pubis and ischium, and the only preserved long bone indicates elongated limbs. The holotype, which is relatively large (>1.35 m) for a basal sauropterygian, has still un-fused halves of neural arches and no distinct neural spine developed yet. The new taxon is assigned to non-cyamodontoid placodonts based on its round girdle elements, the morphology of dorsal-, sacral-, and caudal ribs, the straight medial and mediolateral elements of gastral ribs, and the presence of un-sutured armour plates. In spite of the large size of the holotype, there is evidence that the animal was not yet fully grown, based on the paired neural arches, and general poor ossification of the bones. The un-fused halves of neural arches are interpreted as skeletal paedomorphosis, which is typical for vertebrates with a secondary marine life style. The sacral region seems to be highly flexible.

Key words: Sauropterygia, Placodontia, non-cyamodontoid placodonts, neural arches, paedomorphosis, locomotion/swimming style, Triassic, Muschelkalk, Netherlands.

Nicole Klein [nklein@uni-bonn.de], Steinmann-Institute, Paleontology, University of Bonn, Nussallee 8, 53115 Bonn, Germany; Torsten M. Scheyer [tscheyer@ pim.uzh.ch], Paleontological Institute and Museum, University of Zurich, Karl Schmid-Strasse 4, CH-8006 Zurich, Switzerland.

This is an open-access article distributed under the terms of the Creative Commons Attribution License (for details please see creativecommons.org), which permits unrestricted use, distribution, and reproduction in any medium, provided the original author and source are credited. 
Forif Full text $(1,147.5 \mathrm{kB})$

For 8 Supplementary file $(21.2 \mathrm{kB})$ 